\title{
Erratum
}

Journal of Microbiology (2018) Vol. 56, No. 8, pp. 542-548

DOI 10.1007/s12275-018-8145-9

\section{Flavobacterium parvum sp. nov., isolated from soil polluted by sewer water}

\author{
Hyun Seo Lee, Woon Mo Hwang, Keunsoo Kang, and Tae-Young Ahn
}

Department of Microbiology, College of Natural Sciences, Dankook University, Cheonan 31116, Republic of Korea

In the article by Lee et al. published in Journal of Microbiology 2018; $56,542-548$, The KACC $19447^{\top}$ on $26^{\text {th }}$ line of $4^{\text {th }}$ paragraph in the section of 'Description of Flavobacterium parvum sp. nov.' on page 546 should be corrected in KACC $19448^{\top}$.

The sentence should have read: The type strain, $\mathrm{HS}_{16}{ }^{\top}\left(=\mathrm{KACC}_{19448^{\top}}\right.$, = JCM $32368^{\top}$ ), was isolated from soil polluted by sewer water in Cheonan, South Korea.

We apologize for any inconvenience that this may have caused. 